Atmos. Chem. Phys., 14, 1039-1053, 2014

www.atmos-chem-phys.net/14/1039/2014/

doi:10.5194/acp-14-1039-2014

(c) Author(s) 2014. CC Attribution 3.0 License.

\title{
Decadal-scale responses in middle and upper stratospheric ozone from SAGE II version 7 data
}

\author{
E. E. Remsberg \\ NASA Langley Research Center, 21 Langley Blvd., Mail Stop 401B, Hampton, VA 23681, USA \\ Correspondence to: E. E. Remsberg (ellis.e.remsberg@nasa.gov) \\ Received: 6 June 2013 - Published in Atmos. Chem. Phys. Discuss.: 5 August 2013 \\ Revised: 17 December 2013 - Accepted: 18 December 2013 - Published: 29 January 2014
}

\begin{abstract}
Stratospheric Aerosol and Gas Experiment (SAGE II) version 7 (v7) ozone profiles are analyzed for their decadal-scale responses in the middle and upper stratosphere for 1991 and 1992-2005 and compared with those from its previous version 6.2 (v6.2). Multiple linear regression (MLR) analysis is applied to time series of its ozone number density vs. altitude data for a range of latitudes and altitudes. The MLR models that are fit to the time series data include a periodic $11 \mathrm{yr}$ term, and it is in-phase with that of the $11 \mathrm{yr}$, solar UV (Ultraviolet)-flux throughout most of the latitude/altitude domain of the middle and upper stratosphere. Several regions that have a response that is not quite in-phase are interpreted as being affected by decadal-scale, dynamical forcings. The maximum minus minimum, solar cycle (SClike) responses for the ozone at the low latitudes are similar from the two SAGE II data versions and vary from about 5 to $2.5 \%$ from 35 to $50 \mathrm{~km}$, although they are resolved better with v7. SAGE II v7 ozone is also analyzed for 1984-1998, in order to mitigate effects of end-point anomalies that bias its ozone in 1991 and the analyzed results for 1991-2005 or following the Pinatubo eruption. Its SC-like ozone response in the upper stratosphere is of the order of $4 \%$ for 1984-1998 vs. 2.5 to $3 \%$ for $1991-2005$. The SAGE II v7 results are also recompared with the responses in ozone from the Halogen Occultation Experiment (HALOE) that are in terms of mixing ratio vs. pressure for 1991-2005 and then for late 19922005 to avoid any effects following Pinatubo. Shapes of their respective response profiles agree very well for 1992-2005. The associated linear trends of the ozone are not as negative in 1992-2005 as in 1984-1998, in accord with a leveling off of the effects of reactive chlorine on ozone. It is concluded that the SAGE II v7 ozone yields SC-like ozone responses and trends that are of better quality than those from v6.2.
\end{abstract}

\section{Introduction}

Analysis results have been reported for the $11 \mathrm{yr}$ solar cycle (SC) responses (maximum (max) minus minimum (min) from 2 to $4 \%$ ) and the trends in upper stratospheric ozone from long-term satellite measurements (e.g., Dhomse et al., 2011; McLinden and Fioletov, 2011; Remsberg and Lingenfelser, 2010; Fioletov, 2009; McCormack et al., 2007; Randel and Wu, 2007; Soukharev and Hood, 2006; and Lee and Smith, 2003). However, there has been some disagreement between the response profiles from stratospheric models and from the analyzed data sets (WMO, 2007). Fioletov (2009) reported that he had difficulty in obtaining an accurate $11 \mathrm{yr}$ response for observed upper stratospheric ozone from a time series of "merged, partial column ozone data" from the set of successive, satellite Solar Backscatter UltraViolet (SBUV) instruments, even though he was able to resolve its 27 day ozone response. McLinden and Fioletov (denoted MF, 2011) went further and calculated an ozone partial column vs. pressure response from the Stratospheric Aerosol and Gas Experiment (or SAGE II) version 6.2 (v6.2) data that agreed with that from SBUV, but only after making use of responses and trends in temperature that were smaller than indicated by the operational temperatures archived along with the SAGE II ozone.

Ozone responses to variations of the UV (Ultraviolet) flux ought to be very nearly the same for each solar cycle. However, responses diagnosed from the satellite data of the past three decades may also contain biases from concurrent trends in ozone due to changes in the reactive chlorine, due to perturbations from the major volcanic eruptions of 1982 and 1991, or because of uncertainties for the time series of ozone data from the SBUV sensors on successive operational 
satellites. Randel and Wu (denoted RW, 2007), among others, used an equivalent effective stratospheric chlorine (EESC) quantity as a proxy for accounting for the ozone trends of 1979-2005, due to the nonlinear changes in reactive chlorine. However, MF cautioned that the effects of EESC changes depend on the specific units for a given ozone data series, i.e., number density vs. altitude or partial column vs. pressure. Soukharev and Hood, (denoted SH, 2006) found that simple, linear trend terms were adequate for an accounting of the effects of the changing chlorine in shorter ozone time series. To reduce the perturbing effects from volcanic activity, Lee and Smith (2003) excluded data from their ozone series for many months following major eruptions.

Remsberg and Lingenfelser (denoted RL, 2010) diagnosed decadal-scale responses from the SAGE II v6.2 ozone time series of 1991-2005, and they found good consistency for the shape of its response profiles in the upper stratosphere vs. those from a representative model and from the Halogen Occultation Experiment (or HALOE) ozone. Their SAGE II responses were in terms of number density vs. altitude, while the ones from HALOE were for mixing ratio vs. pressure. However, the response profiles from the model and the observations diverged above $50 \mathrm{~km}$.

The current study is an update of the work of RL, using the newly released SAGE II, version 7 (or v7), ozone that is described in Kyrölä et al. (2013) and in Damadeo et al. (2013) (see also https://eosweb.larc.nasa.gov/project/sage2/sage2_ release_v7_notes). Time series analyses are conducted for the period 1991-2005, as in RL, and also 1984-1998 to minimize the effect of end-point anomalies in the ozone following the Pinatubo eruption of 1991. In addition, results are shown for 1992-2005, in order to assess the effects of the eruption on the trends and the analyzed responses. The use of linear trends for the three sets of time series is similar to the piecewise linear trend approach used by Kyrölä et al. (2013), although they did not focus on the character of their analyzed SC response profiles.

In the present study proxy terms for the quasi-biennial oscillation (QBO) and the solar cycle are not used, in order to be consistent with the previous multiple linear regression (MLR) analyses of RL and to show results from just updating SAGE II ozone from v6.2 to v7. Section 2 illustrates one aspect of the v7 ozone that has led to the improvements in the current results. It is also shown that throughout the latitude/altitude domain, the $11 \mathrm{yr}$ or decadal-scale responses are almost always in-phase with the solar flux maximum and are thereby nearly equivalent to those obtained from a solar UV proxy. The SC-like response profiles from v7 and v6.2 are compared at low latitudes, along with those from the HALOE ozone and from a representative model. Section 3 shows the SC-like responses from SAGE II for both 1984-1998 and 1992-2005, in order to minimize perturbations in the ozone following the eruption of Pinatubo. The distributions of associated trends in the ozone are also compared for the two periods and then related to model simulations of the effects from changes in reactive chlorine that have been reported in the literature. The response profiles from SAGE II (number density vs. altitude) and from HALOE (mixing ratio vs. pressure) are compared and related qualitatively for 1992-2005, or when the recently reported temperature trends are small for the upper stratosphere. Section 4 compares the current SAGE II v7 ozone response profiles with previously published results and comments on several of the discrepancies. Section 5 is a summary of the findings.

\section{Analysis and results for the decadal-scale responses and trends in SAGE II v7 ozone}

Periodic and linear trend terms are applied in the MLR model fits of the SAGE II ozone time series for each altitude and latitude bin. The analyses herein are focused on the max minus min responses (in percent) for a periodic $11 \mathrm{yr}$ term as a function of altitude and latitude for the v7 ozone of 1991-2005, as in RL. Responses are obtained at altitudes from 27.5 to $55 \mathrm{~km}$ at increments of $2.5 \mathrm{~km}$ and at twelve latitude bins spaced by $10^{\circ}$ and centered from $55^{\circ} \mathrm{S}$ to $55^{\circ} \mathrm{N}$. The latitude increments for each of the bin-averaged, SR and SS points in an individual time series have a width of $10^{\circ}$ for the higher latitudes $\left(35,45\right.$, and $\left.55^{\circ}\right)$, but widen to $20^{\circ}$ at the lower $(5,15$, and $25^{\circ}$ ) latitudes to accommodate the fewer samples there. A total of 144 ozone time series are analyzed.

A low altitude limit of $27.5 \mathrm{~km}$ was chosen for the analyses to avoid significant interfering effects of the volcanic aerosols on the retrieved ozone and because the period of the QBO forcing for ozone is somewhat variable for the lower stratosphere. As in RL, proxy terms are not used for the MLR models. Instead, Fourier analysis of the time series of the residuals after removing the seasonal terms almost always indicates that there are two significant, interannual terms having periods of order of 28 (QBO-like) and 21 months (subbiennial term denoted as IA). The IA term is the result of the difference interaction between the QBO and annual cycles (Dunkerton, 2001; Tung and Yang, 1994). Its period varies from 20 to 22 months, most likely because of slight variations in the period of the actual QBO forcing. Remsberg et al. (2001, Fig. 4d) contains an example plot of the diagnostic that is used to check for the presence of periodic structure in the residual time series, and Remsberg (2008, Figs. 7, 8) gives the latitude/pressure distributions of the amplitudes of the QBO and IA terms in the HALOE ozone data. Those two interannual terms are also present in the SAGE II v7 ozone time series, so they are included in the current MLR models along with the annual and semiannual terms. Amplitude of the IA term is often near to that of the QBO in the subtropical middle stratosphere, and its inclusion in the MLR models leads to improved fits for the $11 \mathrm{yr}$ and trend terms at those latitudes.

Salby et al. (1997) and Baldwin and Dunkerton (1998) noted that there is a decadal-scale interaction between the 
QBO and biennial oscillations that can mimic the solar cycle, while Smith and Matthes (2008) modeled the response of ozone to the SC in the presence of the QBO cycle. However, the present analysis simply includes an $11 \mathrm{yr}$ periodic term as part of the MLR fit to the data. Whenever its maximum occurs within one year of the time of the solar UV-flux maximum, the $11 \mathrm{yr}$ term is judged as in-phase with and primarily as a response to the solar UV-flux forcing. Regions where it is not in-phase indicate the presence of a decadalscale, dynamical forcing or a nonperiodic, episodic forcing.

The analyses follow a two-step approach to account for the effects of serial correlation at lag 1 in the data, following Tiao et al. (1990, Appendix A) and Remsberg (2008, Sect. 2.2). Initially, the MLR model terms are fit to the data time series for a given altitude and latitude bin. Next, the time series of the model/data residual is analyzed for its lag-1 autocorrelation coefficient, $\varphi$. Then, the model terms are reformulated to include the effects of $\varphi$, and the data time series are refit to get the final regression coefficients for each term.

Several improvements for the SAGE II v7 data affect the results herein. The sunrise (SR) and sunset (SS) profiles are registered in altitude more accurately than before because of a correction in the use of the associated solar ephemeris data within the SAGE II algorithms (Damadeo et al., 2013, Fig. 2). Seasonal variations in the ozone are resolved more accurately, as a result. That revision has led to significant reductions in the MLR ozone residuals at low and middle latitudes. The $\varphi$ values for the transformed terms in the MLR models are now larger for $\mathrm{v} 7$ than for v6.2, and they affect the coefficients of the analyzed trend terms and to a lesser extent the $11 \mathrm{yr}$ terms. The limited duration, solar scan events of mid-1993 through early 1994 and their associated SAGE II profiles are not part of the v7 data set. Some spuriously low, SR ozone data profiles are screened out for the low latitudes in September and November of 1991 because of excessive extinction effects from the Pinatubo aerosol layer. A very few v7 ozone profiles are also not retained because their associated errors exceed $10 \%$ within the altitude range of $50-27.5 \mathrm{~km}$. Finally, continuous temperature time series from the Modern-Era Retrospective Analysis for Research and Applications (MERRA) system (Rienecker et al., 2008) are employed for the removal of Rayleigh scattering effects in the v7 algorithm. Rayleigh effects are a significant correction for retrievals of the SAGE II ozone above about $55 \mathrm{~km}$ (Chu et al., 1989).

The bin-averaged SR and SS data points have been assembled into a single time series, in order to decrease the time intervals between their observations at a latitude zone. This approach is helpful because having twice as many points that are separated by smaller intervals means that the semiannual and annual terms can be resolved better. However, the small, but systematic SR/SS differences of the ozone of the upper stratosphere and the mesosphere can lead to significant variations for the de-seasonalized, time series residuals. In fact, those residuals are characterized by lag-1 autocorrelation co-
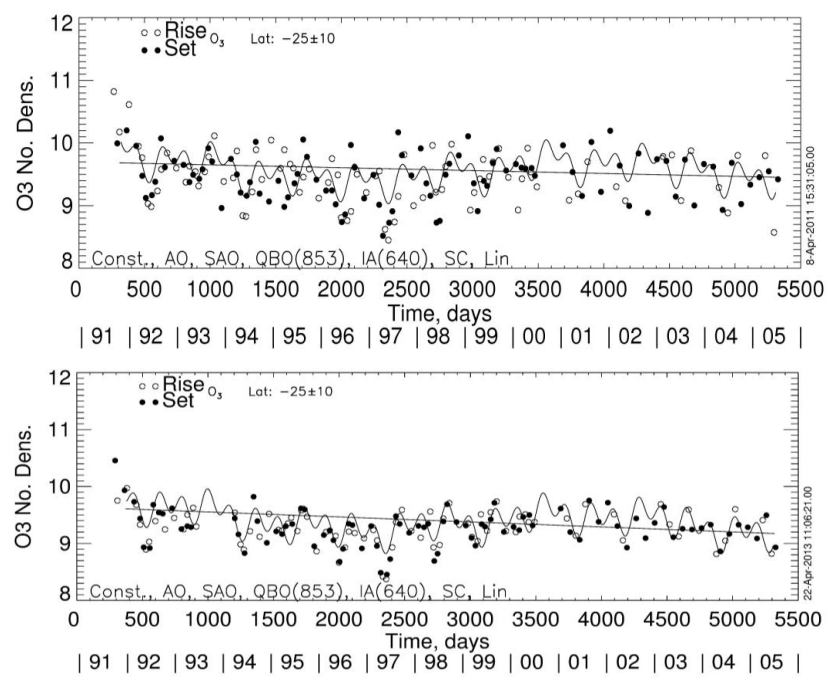

Fig. 1. Time series of bin-averaged SAGE II SR and SS ozone number density measurements (in $\mathrm{cm}^{-3}$ multiplied by $10^{-11}$ ) at $25^{\circ} \mathrm{S}$ and $37.5 \mathrm{~km}$ (top) v6.2, (bottom) v7. Terms of the MLR model are indicated at the lower left, where SC refers to an $11 \mathrm{yr}$ sinusoid term. The oscillating solid curve is the model fit to the data, while the straight line curve is the sum of just the constant and linear trend terms.

efficients that are near zero or slightly negative. The approach used herein is to analyze the time series of SR points and then series of SS points. The constant terms of the MLR models are slightly different from the analyses of each series. Following that, the SR points and the SS points of the separate time series are adjusted by half that difference before combining both sets of points into a single time series for the final MLR analysis. The lag-1 autocorrelation coefficients are less negative or more positive for the residuals of the final time series, as expected, since changes in zonal mean atmospheric ozone tend to occur slowly or over weeks rather than days.

Figure 1 compares the v7 with the v6.2 ozone time series for $25^{\circ} \mathrm{S}$ and $37.5 \mathrm{~km}$ that was analyzed previously by RL (their Fig. 2). The solid oscillatory curve is the fit to the points based on all the terms of the MLR model, while the straight line is the sum of just the constant and linear trend terms. In addition to the seasonal terms, one can clearly see that there is an $11 \mathrm{yr}$ (or SC-like) term that is closely in-phase with the solar UV-flux maxima that occurred in 1991 and in 2002. At this point it is noted that number density is plotted as increasing on the $y$ axis in Fig. 1, even though it undergoes a nearly exponential decrease with altitude in the upper atmosphere. Nevertheless, when the UV flux reaches its maximum in 1991 and 2002, Fig. 1 shows that ozone also attains its maximum (production) value at those times. A primary difference in Fig. 1 between the time series for v7 vs. v6.2 is that the data points for $\mathrm{v} 7$ are defining the seasonal cycles more clearly; in general, the amplitudes of the annual and especially the semiannual terms are larger with the analysis of 


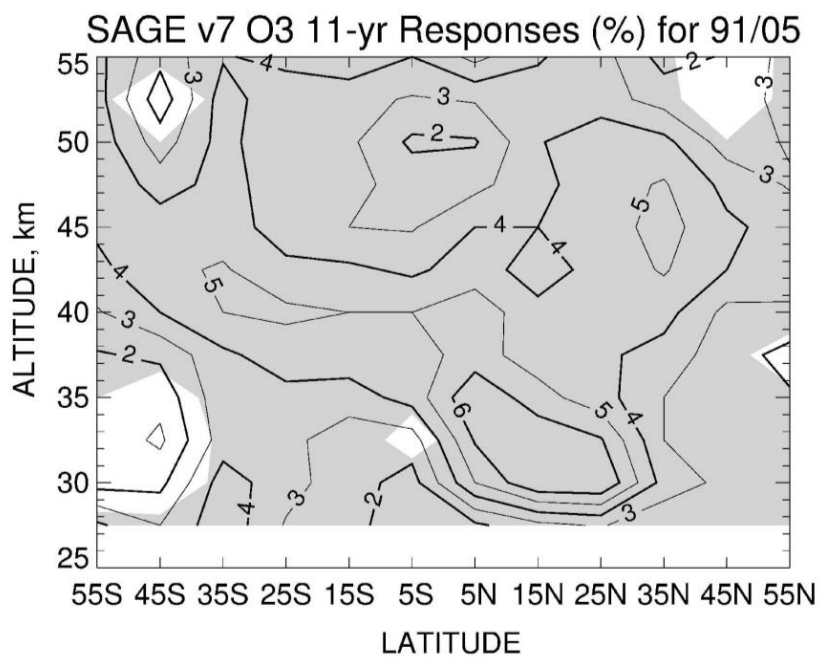

Fig. 2. Contour plot of the maximum minus minimum, $11 \mathrm{yr}$ response (in percent) for the SAGE II v7 ozone of September 1991 through August 2005. Contour interval is $1.0 \%$. Shading denotes confidence intervals $(\mathrm{CI})>90 \%$ for the responses.

the v7 data. That outcome is due to the more correct application of the solar ephemeris data for the registration of the SR and SS profiles. As a result, the residuals are smaller from the MLR fit to the $\mathrm{v} 7$ data, and the autocorrelation effects are larger. For instance, the coefficient $\varphi$ is 0.44 for v7, but only 0.05 for the v6.2 time series of Fig. 1. It was also realized that RL had inadvertently obtained bin-averaged points for their SAGE II ozone time series of 1991-2005 based on the poleward extremes for the latitudinal sweeps of the separate sunrise and sunset tangent track measurements, but using the dates for those extremes from the HALOE experiment rather than basing them on the actual beginning and ending dates for the sweeps of SAGE II. That incorrect grouping for the SAGE II profiles by RL also reduced slightly the accuracy of their fits for the seasonal terms. That error has been corrected for the results of Fig. 1 and for the remaining analyses herein, although it does not alter the conclusions of RL.

Figures 2 and 3 represent an update of the MLR analysis results shown in RL for v6.2 (their Figs. 6-7), but based now on the v7 data. Figure 2 is the distribution of the $11 \mathrm{yr}$ responses, and they are of the order of 3-5\% throughout most of the region with a minimum near $2 \%$ at the tropical stratopause. The analyzed responses increase to $6 \%$ in the middle stratosphere of the northern subtropics, where Lee and Smith (2003) and RL indicated that there was an anomalous ozone forcing for some months following the Pinatubo event. A likely explanation for that ozone increase is from the effects of "de-noxification" or the temporary conversion of $\mathrm{NO}_{\mathrm{x}}$ to $\mathrm{HNO}_{3}$ in the presence of enhanced amounts of aerosols. Significance for the distribution of the amplitudes in Fig. 2 is indicated by the shading, which shows the domain of the probability or the $90 \%$ confidence interval (CI)

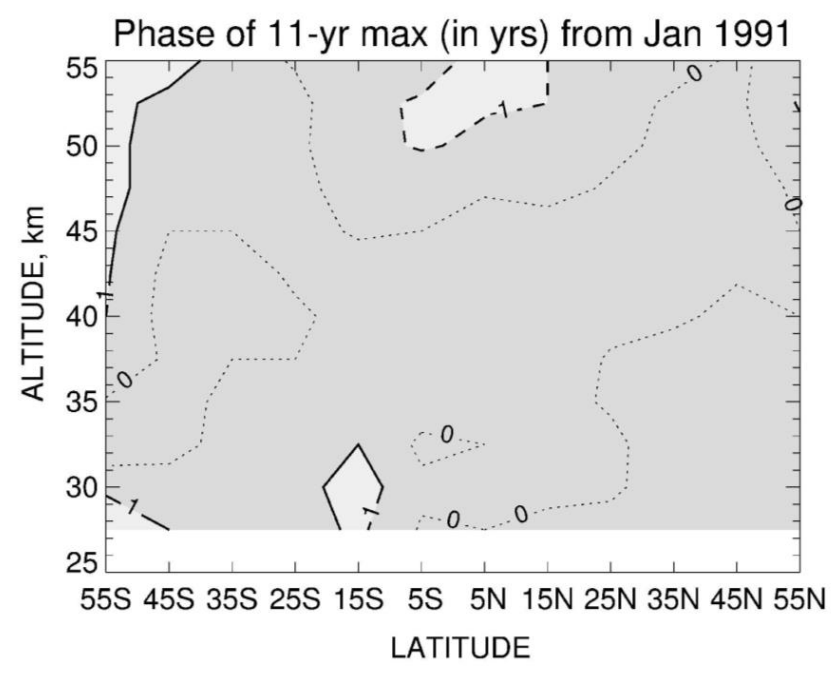

Fig. 3. Contour plot of the phase variations (in years from January 1991 or 2002) of the $11 \mathrm{yr}$ response terms in Fig. 2. Contour interval is $1 \mathrm{yr}$. The phase domain of $\pm 1 \mathrm{yr}$ is shaded and is considered as in-phase with the solar UV-flux maximum.

that the $11 \mathrm{yr}$ term is present in the zonally binned, ozone time series. Examples of further significance tests are given in Remsberg et al. (2001). Figure 3 is the companion plot of the phases of the $11 \mathrm{yr}$ terms as referenced to January 1991, which is the approximate midpoint time of the maximum for the solar UV flux to the stratosphere. The dark shaded regions in Fig. 3 are where the phases are within $\pm 1 \mathrm{yr}$ of January 1991 and where the $11 \mathrm{yr}$ terms are considered as in-phase with the solar UV flux. Those $11 \mathrm{yr}$ terms are interpreted as the response to the UV-flux variations and are denoted as SC-like. The $11 \mathrm{yr}$ terms in the middle stratosphere of the northern subtropics are also closely in-phase in Fig. 3, even though they include perturbing atmospheric effects following the Pinatubo event.

Figure 4 shows the distribution of the coefficients of the associated linear trend terms for the SAGE II v7 ozone of 1991-2005 in units of percent per decade, along with the shadings for their $90 \%$ and their $70-90 \%$ confidence intervals. Note that these trends are not explicitly related to an EESC term, but do include the linear effects of the relatively small changes in the atmospheric chlorine over this time span. There is much better continuity in the distribution of the trends in Fig. 4 compared to that from v6.2 in RL (not shown, but see their Fig. 8). This finding is expected, given that the accounting for autocorrelation effects in the residuals has a primary effect on the trend terms. The trends from v7 are $-4 \%$ decade $^{-1}$ from 40 to $50 \mathrm{~km}$ but $-2 \%$ decade $^{-1}$ from 30 to $35 \mathrm{~km}$ and also near $55 \mathrm{~km}$. The anomalously large, negative trends above $50 \mathrm{~km}$ that were reported from the v6.2 data (see also RL, Fig. 8) are not present in the analysis of the $\mathrm{v} 7$ ozone. This improvement may be because of 


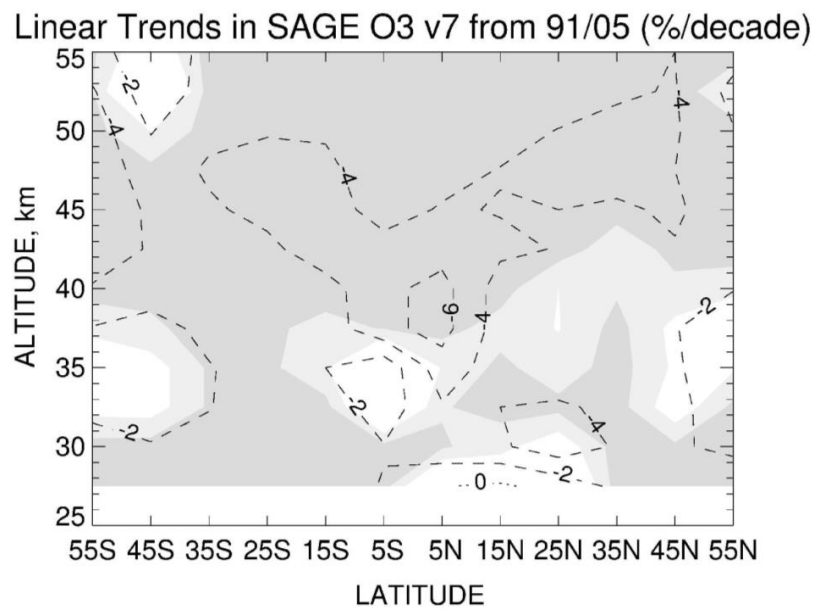

Fig. 4. Contour plot of the linear trend terms $\left(\%\right.$ decade $\left.^{-1}\right)$ from the MLR models for the SAGE II ozone data of 1991-2005. Contour interval is $2 \%$ decade $^{-1}$. Dashed contours denote negative trends, and the dotted contour is where the trends are zero. Darker shading denotes where $\mathrm{CI}>90 \%$ for the trends; lighter shading has $70 \%<\mathrm{CI}<90 \%$.

the use of the MERRA temperatures for the mesosphere in the v7 retrieval algorithm, particularly after 2000.

Figure 5 displays the distribution of the SC-like response amplitudes for 1991-2005, according to the values that the $11 \mathrm{yr}$ terms would have on January 1991. In other words, the $11 \mathrm{yr}$ amplitudes of Fig. 2 were adjusted for the fact that the phases of Fig. 3 were slightly lagging or leading the assigned time for the solar UV-flux maximum. Maximum responses of order $2.5-4.5 \%$ occur in the upper stratosphere at low to middle latitudes, decreasing to $2-3 \%$ at the higher latitudes. Although the SC-like responses are less than $2 \%$ in the middle stratosphere of the southern tropics, the phase-adjusted, SC-like responses of the northern subtropics are still anomalously large for this period because of the end-point anomalies from the Pinatubo event for the trend term of the MLR model fit.

Figure 6 compares the SC-like ozone response results from SAGE II v7 and v6.2 for just the low latitudes. Specifically, the separate response profiles are averaged for each data set across the latitudes of $15^{\circ} \mathrm{S}, 5^{\circ} \mathrm{S}, 5^{\circ} \mathrm{N}$, and $15^{\circ} \mathrm{N}$. Because of the $20^{\circ}$ width of each latitude bin, the average response profiles are characteristic of the latitude range of $25^{\circ} \mathrm{S}$ to $25^{\circ} \mathrm{N}$. There is little difference in the SC-like profiles from the two data versions. Figure 6 also shows the SC-like response profile obtained by RL for the HALOE ozone mixing ratio vs. pressure profiles, and they range from 0.5 to $2.5 \%$ for the period 1991-2005. The SC-like response from HALOE is smaller than that from SAGE II because ozone is more nearly conserved on pressure than on altitude surfaces. The HALOE result indicates a small but increasing response in the mesosphere that is similar in shape to that from SAGE II, although neither is really significant. Fig-

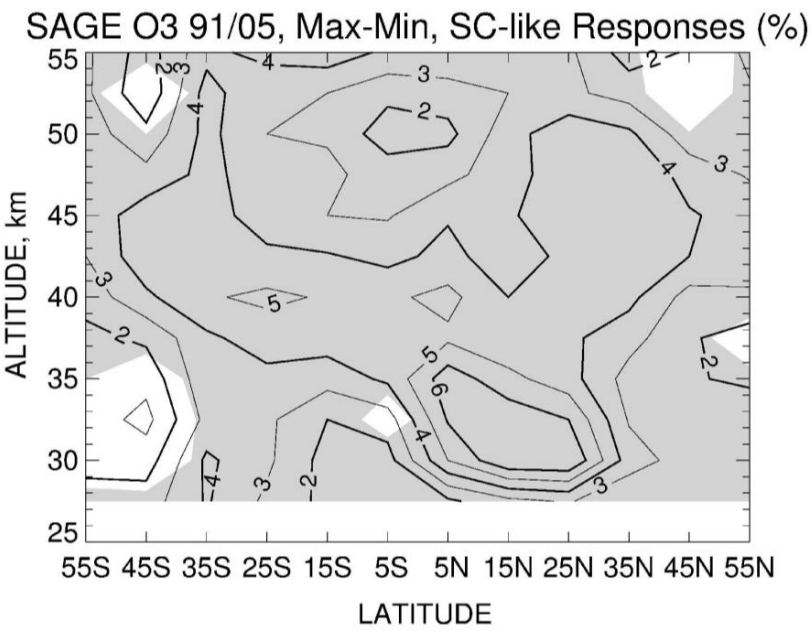

Fig. 5. As in Fig. 2, but the SAGE II max minus min, 11 yr responses have been adjusted to be in-phase for that of a solar UV-flux maximum in January 1991. Shading denotes where CI > $90 \%$.

ure 6 also includes a low latitude response profile from the interactive, chemical-dynamical-radiative model of Brasseur (1993). There is good agreement between the response profiles from HALOE and the model, both of which are given in terms of mixing ratio vs. pressure-altitude. They differ only in the lower mesosphere, where the response in the model is zero to slightly negative.

Estimates of total 1- $\sigma$ error are shown in Fig. 6 for the SAGE II v7 and the HALOE v19 SC-like response profiles. The total error has two components. The first component is the uncertainty for the amplitude of the $11 \mathrm{yr}$ response, which approximates very closely to the SC-like response in most instances. This component of the error increases with altitude in a manner that agrees with the doubling of the uncertainties from 3 to $6 \%$ for the SAGE II ozone from 36 to $39 \mathrm{~km}$ (Fioletov et al., 2006). Those errors are much larger than the amplitude of the SC response and reflect the effects of the decreasing signal to noise with altitude for the measured SAGE II and HALOE profiles. In fact, the amplitudes of all the periodic terms are small at altitudes where ozone is in photochemical balance. Thus, the analyzed SC-like responses from occultation data will not be significant for the uppermost stratosphere and into the mesosphere unless one analyzes data averages across many profiles. A second error component accounts for the variation of the response profiles from the separate latitude bins about the average of their responses across $25^{\circ} \mathrm{S}-25^{\circ} \mathrm{N}$. That component is large near $30 \mathrm{~km}$ because of the perturbation in the retrieved ozone in the northern but not the southern subtropics following the Pinatubo event. This component of the error is larger for SAGE II than for HALOE because the measured signals for the SAGE II ozone are more sensitive to the interfering extinction from the aerosols. However, both error components for SAGE II are essentially the same from the v7 and v6.2 
SC-like O3 Response: SAGE, HALOE, Model

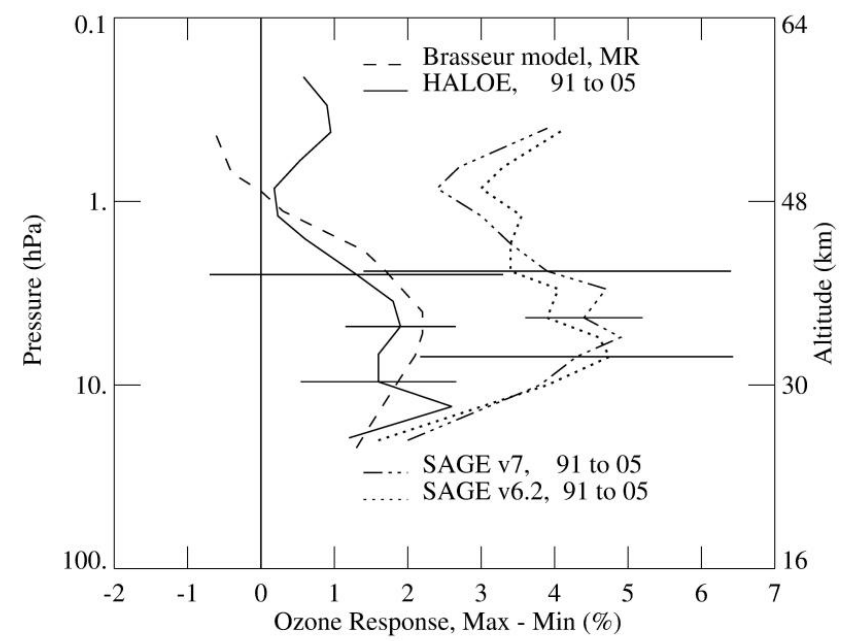

Fig. 6. Profiles of the average SC-like ozone responses (in percent) at the lower latitudes from the Brasseur model (dashed), the HALOE data (solid), and the SAGE II v6.2 (dotted) and v7 (dashdot-dot-dot) data from 1991 to 2005. Horizontal bars are the RSS total errors for the HALOE and the SAGE II v7 ozone responses (see text).

data (not plotted). Estimates of the total error are obtained by adding the two components using the root of sum of squares (RSS) method. It is also noted that the SC-like response profiles of ozone in Fig. 6 are not as smooth for SAGE II vs. HALOE. Part of that difference is because the SAGE II measurements have a higher vertical resolution. In addition, atmospheric ozone is not conserved as well at an altitude level (SAGE II) as on a pressure surface (HALOE).

\section{Effects of dynamical forcings and/or end-point anomalies}

Dynamical perturbations following the eruption of Pinatubo and/or end-point anomalies may be imparting biases for the analyses of linear trend terms from the time series of 19912005 and to a lesser extent for their associated SC-like responses. Two alternate time periods are evaluated for those effects: 1984-1998, which bridges the 1991 period; and late 1992-2005, which eliminates an initial segment of the data following Pinatubo.

\subsection{Analyses for the period 1984-1998}

The SAGE II v7 results for 1984-1998 are shown in Figs. 7-9. Figure 7 is the distribution of the responses for the $11 \mathrm{yr}$ terms. The max minus min responses are on the order of $4 \%$ from 40 to $50 \mathrm{~km}$ but decrease to $2-3 \%$ near $30 \mathrm{~km}$, and there is no minimum response at the tropical stratopause like that of Fig. 2 for 1991-2005. An anomalous response of near

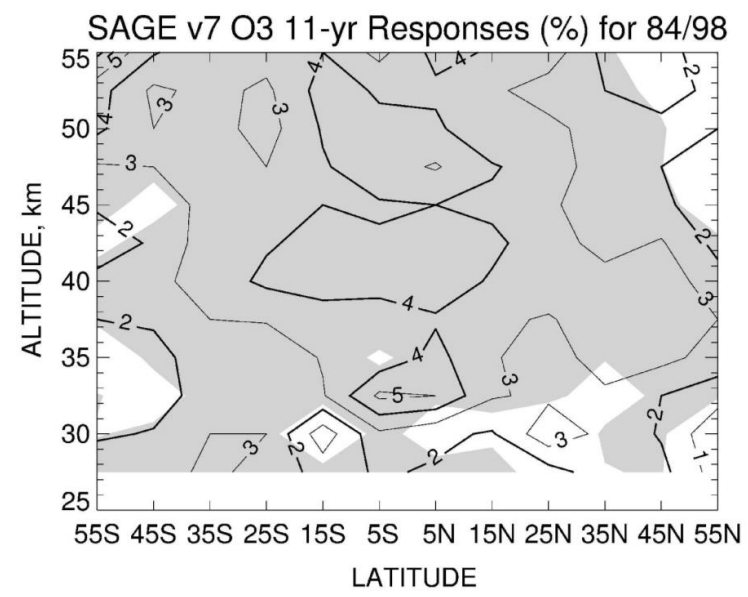

Fig. 7. As in Fig. 2, but the max minus min variations are from the SAGE II data from November 1984 through October 1998.

$5 \%$ appears in a small region between 30 and $35 \mathrm{~km}$ at the Equator, but there is no indication of perturbing effects following Pinatubo in the northern subtropics. Figure 8 shows the distribution of the phases of the $11 \mathrm{yr}$ terms. Again, they are in-phase with the solar UV flux throughout most of the latitude/altitude domain, indicating that there are no significant, out-of-phase dynamical forcings affecting the results in the upper stratosphere. However, at the Equator and between 30 and $35 \mathrm{~km}$ the $11 \mathrm{yr}$ term has its diagnosed maximum closer to 1992-1993 than to January 1991. That phase lag of 1-2 yr exhibits good continuity across the latitude bins of the tropical middle stratosphere. The $11 \mathrm{yr}$ terms are also not quite in-phase at the highest latitudes of Fig. 8, possibly due to the effects of decadal-scale, dynamical forcings. Figure 9 shows the distribution of the coefficients of the linear trend terms, which are very similar to the results obtained by Wang et al. (2002) for the period of 1984-1999. The clear variation with latitude at $40-45 \mathrm{~km}$ is explained by the effects of changes in the reactive chlorine during this period (cf., Fleming et al., 2011, their Fig. 3). The anomalously large, negative trend of $-8 \%$ decade $^{-1}$ and centered at $32.5 \mathrm{~km}$ and $5^{\circ} \mathrm{N}$ in Fig. 9 is nearly offset in this $14 \mathrm{yr}$ time span by the large positive, max minus min, response of $5 \%$ (Fig. 7) that is not in-phase with the solar cycle (Fig. 8). Elsewhere, the succession of the trends from Fig. 9 and then Fig. 4 reinforces the findings of others that the large declines in ozone of the 1980s were leveling out during the period 1991-2005 and beyond (WMO, 2007, 2011; Kyrölä, et al., 2013).

Any perturbation to the ozone that occurs at the beginning of the time series of 1991-2005 will act as an end point anomaly for the determination of the linear trend term and will confound the coefficient of the $11 \mathrm{yr}$ term. Figure 7 shows that the region of rather large, $11 \mathrm{yr}$ responses in the northern subtropics at $30-35 \mathrm{~km}$ are smaller than in Fig. 2, despite the fact that the data period following Pinatubo contributes to both time series distributions. As a further 


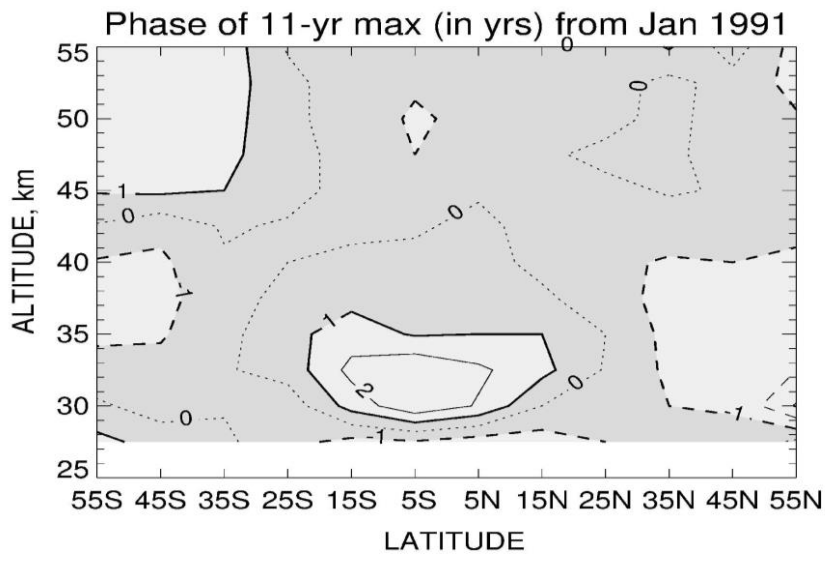

Fig. 8. As in Fig. 3, but the phases of the $11 \mathrm{yr}$ terms are from the SAGE II data from November 1984 through October 1998.

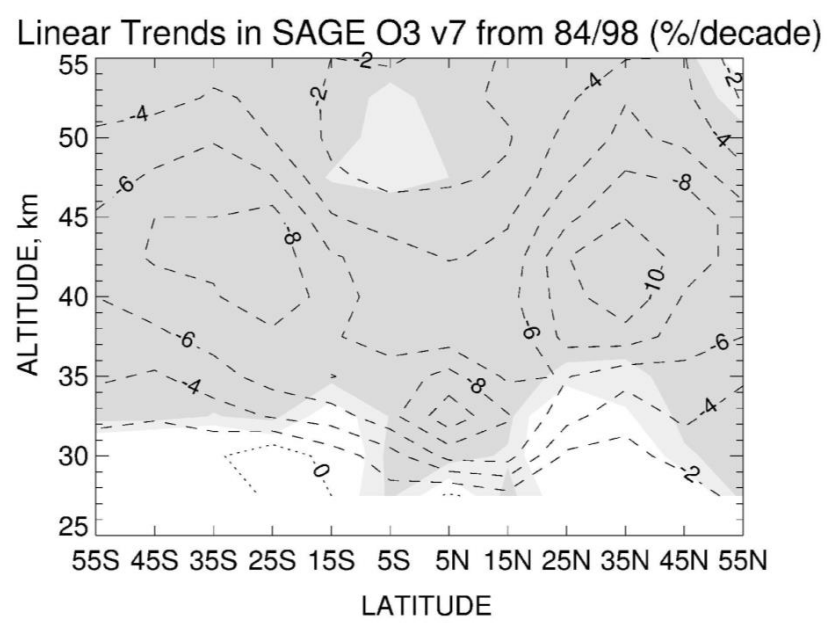

Fig. 9. As in Fig. 4, but the trends are from the SAGE II data from November 1984 through October 1998.

example, Fig. 10 is the ozone time series from 1984 to 1998 at $5^{\circ} \mathrm{N}$ and $30 \mathrm{~km}$. One can see that the MLR model terms fit the data well and that the Pinatubo event has less of an effect on the diagnosed linear trend term.

The responses for 1984-1998 have a 1-2 yr phase lag in the tropical middle stratosphere, according to Fig. 8. It is inferred that some feature of the time series prior to 1991 is not being fit very well. An important consideration for the acceptance of the terms of an MLR model is an examination of the time series of its residual to be sure that it contains no remaining periodic structure (e.g., Remsberg et al., 2001). As an example, the MLR fit to the ozone time series of $5^{\circ} \mathrm{N}$ and $30 \mathrm{~km}$ in Fig. 10 is systematically high in 1989-1990, followed by a slight low bias in 1991-1992. Those results suggest that the true amplitude of the QBO may have been larger than average for that interval and that this term of the MLR model did not account for that interannual variation very well. As a result, the analyzed $11 \mathrm{yr}$ term is influenced by the relative

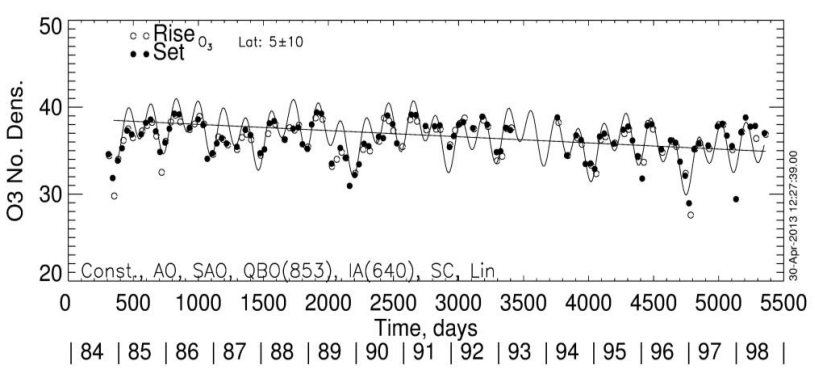

Fig. 10. As in Fig. 1, but for the $\mathrm{v} 7$ ozone at $5^{\circ} \mathrm{N}$ and $30 \mathrm{~km}$ from SAGE II for 1984-1998.

minimum in the observed ozone of 1989-1990, and the maximum for that diagnosed term occurs in 1992 rather than near the beginning of 1991 .

Hood et al. (2010) and Dhomse et al. (2011) tested for the likelihood of a separate perturbation from the El NiñoSouthern Oscillation (ENSO) of 1988-1989 and its possible reinforcement of the amplitude of the QBO. Typically, ENSO anomalies at $16 \mathrm{~km}$ ascend to $30 \mathrm{~km}$ about 18 months later, or in this case, near to the time of the Pinatubo eruption in June 1991 (Garcia et al., 2007). Thus, Hood et al. (2010) and Dhomse et al. (2011) added a term to their regression models related to a lagging ENSO index, but they found that it had very little effect at $30 \mathrm{~km}$ and above. Hood et al. (2010) and Chipperfield et al. (1994) also reported on a negative correlation between tropical ozone and $\mathrm{NO}_{2}$ at $30-32 \mathrm{~km}$ from the effects of a vertical advection of $\mathrm{NO}_{\mathrm{y}}$ associated with the QBO forcing. Since Fig. 8 shows good coherence for the 1$2 \mathrm{yr}$ phase lag of the maxima of the $11 \mathrm{yr}$ terms across tropical latitudes and from 30 to $35 \mathrm{~km}$, it is presumed that those $11 \mathrm{yr}$ terms are confounded with the ENSO/QBO forcing and with the associated chemical/transport effects at that time.

Figure 11 displays the distribution of the SC-like response amplitudes for 1984-1998, according to the values that the $11 \mathrm{yr}$ terms would be on January 1991. As for the period 1991-2005 (Fig. 5), the $11 \mathrm{yr}$ amplitudes of Fig. 7 are adjusted for the fact that the phases in Fig. 8 are slightly lagging or leading the assigned time for the solar UV-flux maximum. Since the $11 \mathrm{yr}$ response maximum is lagging January 1991 by a year or more in the tropical middle stratosphere, its estimated SC-like response is reduced to less than $2 \%$. Brasseur (1993) and McCormack et al. (2007) obtained maximum responses of only $2.5-3 \%$ from about 35 to $40 \mathrm{~km}$ from the effects of the UV-flux variations. Analyzed responses of less than $2 \%$ at the higher latitudes in Fig. 11 may also indicate effects of a chemical loss of ozone due to wintertime descent and mixing of $\mathrm{NO}_{\mathrm{x}}$ to lower latitudes that is enhanced at solar maximum (Garcia et al., 1984).

Differences between Figs. 5 and 11 are found for the tropics between 45 and $50 \mathrm{~km}$, where the analyzed SC-like responses are larger for 1984-1998 than for late 1991-2005 by nearly a factor of 2 . Solar flux values were also larger for the 


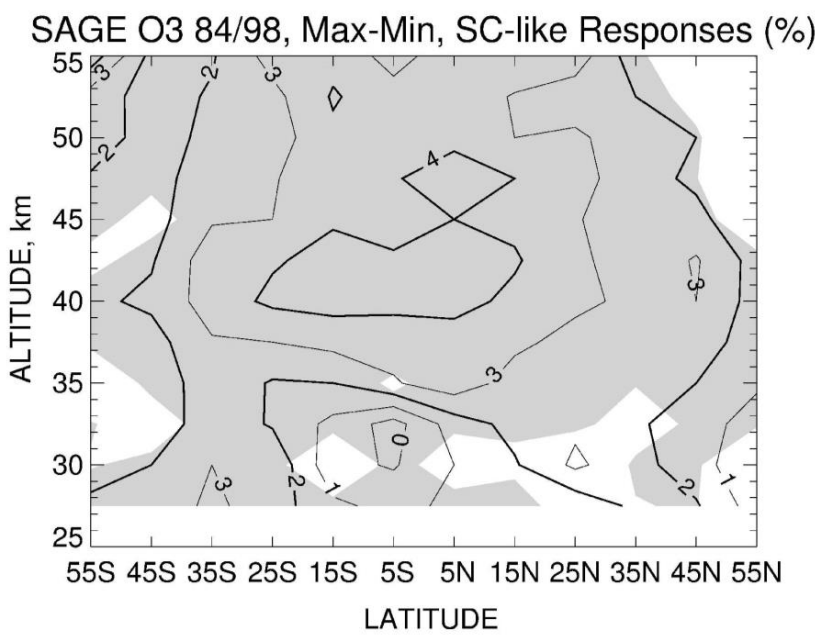

Fig. 11. As in Fig. 5, but the SC-like responses are based on adjustments to Fig. 7 for 1984-1998.

solar maximum centered in 1990-1991 compared with the maximum of 2002 (Smith and Matthes, 2008), but that explains only part of the difference. Another part may be related to a bias in the analyzed ozone trends for one or both periods (cf., Figs. 4 and 9). Analyzed ozone responses are more easily confounded with the trends for the ozone for the relatively short, $14 \mathrm{yr}$ time series of the present study. Since the upper atmospheric ozone decreases are larger in the 1980s than in the 1990s, it is likely that any confounding effects from the trend term are larger for 1984-1998.

Were there any decadal-scale, dynamical forcings and associated temperature variations that were in-phase with the solar UV-flux forcing during 1984-1998, or at least prior to September 1991? To check this possibility, time series of the SAGE II ozone at $5^{\circ} \mathrm{S}$ and $47.5 \mathrm{~km}$ are shown in Fig. 12 for each of the two periods, 1984-1998 and 1991-2005. The data points reveal a pronounced amplitude minimum every year in January/February for the 1980s, but not from 1993 through 1998 in the first series. Pronounced minima occur once again in 1999, 2001, 2003, and 2004 in the second series. The first semiannual term in the MLR model provides a better fit to the time series of 1984-1998 than of 1991-2005. However, the analyzed amplitude of the semiannual term of the MLR model shows little to no change between the two time series; it is the amplitude of the annual term that is larger for 1984-1998 (4.3\%) than for 1991-2005 (3.4\%). As a result, the MLR model residuals are larger for the 1991-2005 series, and its associated SC-like terms are not being resolved as well. The irregular character of the annual ozone minima near the tropical stratopause indicates that they are episodic and short-lived. It is hypothesized that they occur due to secondary, net circulations in response to extratropical gravity wave forcings (Shu et al., 2013) at times of polar winter warming activity (Hitchman and Leovy, 1986; Solomon et al., 1986). The ozone minima indicate a net downward trans-

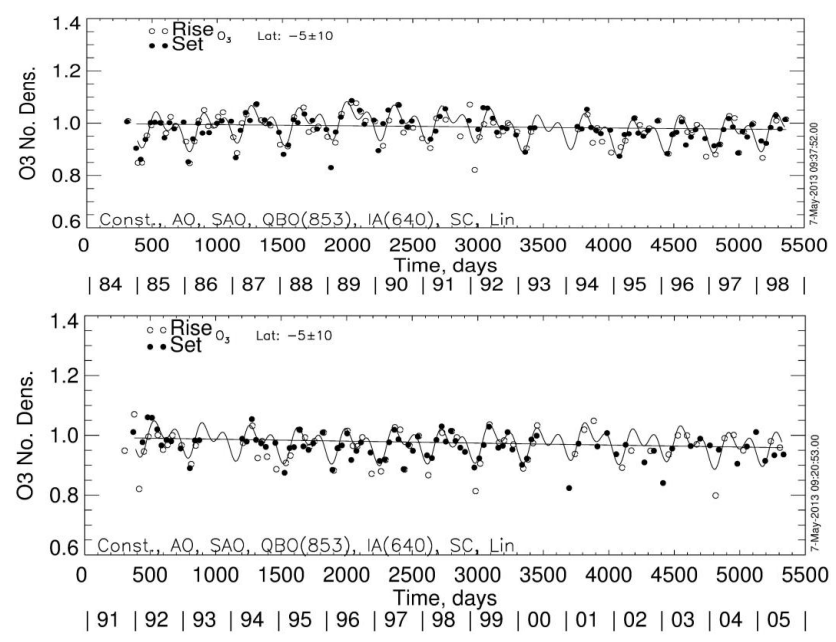

Fig. 12. Time series of SAGE II v7 ozone at $5^{\circ} \mathrm{S}$ and $47.5 \mathrm{~km}$ for (top) 1984-1998 and (bottom) for 1991-2005.

port of air having lower ozone values. Pawson and Naujokat (1999) reported that the Northern Hemisphere, winter polar vortex was unusually stable during successive years through the middle 1990s, which may account for the smaller annual ozone amplitudes during those years. Charlton and Polvani (2007) and Manney et al. (2005) also found evidence for more frequent, sudden stratospheric warming activity in the 1980s and early in the 2000 decade, respectively.

The average, SC-like response profile at low latitudes for the v7 ozone of 1984-1998 in terms of number density vs. altitude is compared in Fig. 13 with the profile for 19912005 that is replotted from Fig. 6. The ozone response from 30 to $35 \mathrm{~km}$ is much smaller for $1984-1998$ because there is less impact for the MLR analyses from the data just following the Pinatubo event that occurs midway in this time series. The total $1-\sigma$ errors at 30 and $35 \mathrm{~km}$ are also reduced significantly and are more nearly equivalent to those from HALOE (cf., Fig. 6). However, the analyzed responses of Fig. 13 at 45 to $50 \mathrm{~km}$ do not differ significantly for the two SAGE II time periods. Dhomse et al. (2011) conducted a regression analysis for the SC-like ozone response from their simulations of ozone based on the dynamical fields in the reanalysis products, ERA-40 and ERA-Interim (EI), but for the longer time span of 1979-2005. They reported better dynamical consistency in the EI reanalysis, so their analyzed results based on EI are considered here. Their analyzed SClike response profile in terms of Dobson units (DU) per kilometer (or equivalent to number density) was shown in Fig. 6 of their original discussion paper; that result is adopted and plotted in Fig. 13, too. Their simulated response profile has a peak value of $4 \%$ near $40 \mathrm{~km}$, and it agrees with the SAGE II v7 responses from 30 to $40 \mathrm{~km}$. Presumably, the effects of any dynamical forcings due to an ENSO and/or following the Pinatubo event are present in the EI product, and that is why the agreement is good from 30 to $40 \mathrm{~km}$. Conversely, their 
SC-like O3 Response: SAGE, Model

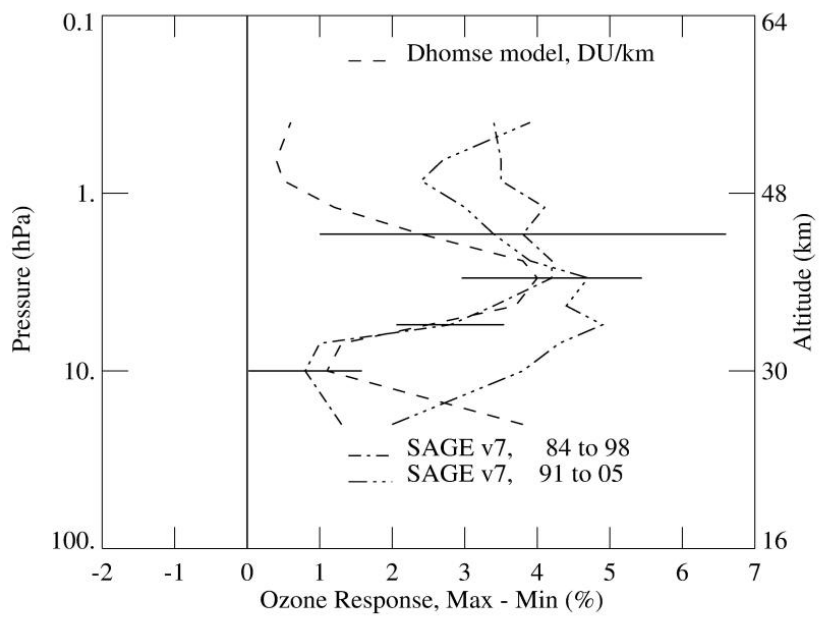

Fig. 13. As in Fig. 6, but the SC-like response profiles are for the model of Dhomse et al. (dashed; DU km ${ }^{-1}$ ) and from SAGE II v7 for 1984-1998 (dash-dot) and for 1991-2005 (dash-dot-dot-dot). Horizontal bars are the RSS errors for the response profile from the SAGE II v7 ozone of 1984-1998.

analyzed SC responses decline sharply from 40 to $50 \mathrm{~km}$ and disagree with those from SAGE II. This altitude region is where both the trends in reactive chlorine and in temperature are important for characterizing the longer-term variations in ozone number density (see also Sect. 3.3).

\subsection{Analyses for the period late 1992-2005}

Lee and Smith (2003) showed that atmospheric forcing effects persisted for some months after the eruption of Pinatubo. Such forcings can lead to end-point anomalies for MLR analyses of ozone time series that begin by late 1991 . The distribution of the SC-like amplitudes was obtained (not shown) for this period in the manner of the results in Figs. 5 and 11 . Then, Fig. 14 shows the analyzed SC-like response profile from SAGE II v7 for the low latitudes for the time series of late 1992-2005, or excluding the first 14 months of data following the Pinatubo event. An analogous response profile for 1992-2005 is shown for the HALOE ozone, but in terms of its mixing ratio vs. pressure values. The response from SAGE II varies from 3 to $4 \%$ between about 35 and $40 \mathrm{~km}$, decreasing to less than $2 \%$ at $30 \mathrm{~km}$ and at $50 \mathrm{~km}$. The SAGE II response at $32.5 \mathrm{~km}$ for 1992-2005 (Fig. 14) is weaker, has a smaller uncertainty, and is more significant than for 1991-2005 (Fig. 6) because of the removal of the data points from the beginning of the time series. Both the SAGE II and HALOE responses appear to be free of the episodic forcing effects from ENSO and following from Pinatubo. The response at $42.5 \mathrm{~km}$ for $1992-2005$ is also weaker than for 1991-2005, but the RSS errors show that it is not very significant. It may be that the rather large de-
SC-like O3 Response: SAGE, HALOE, Model

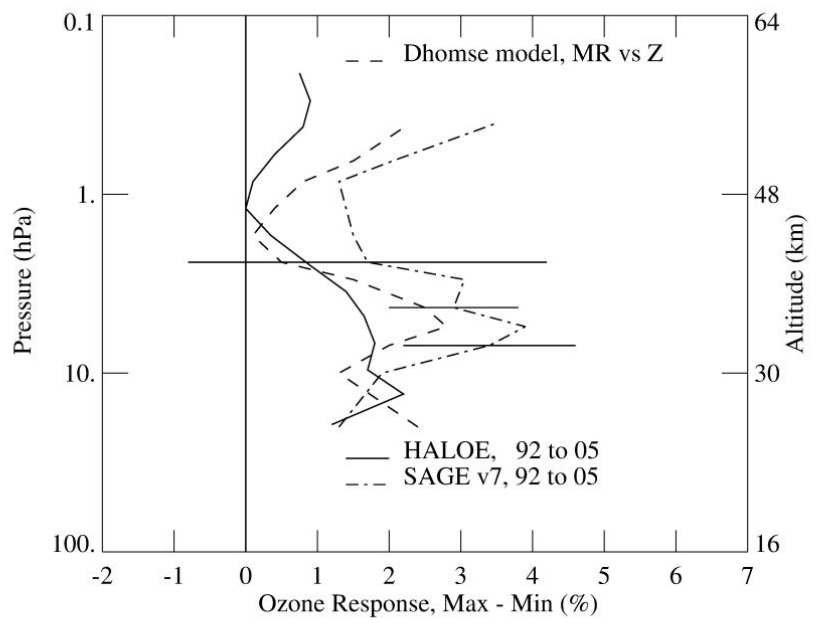

Fig. 14. As in Fig. 13, but the SC-like response profiles are for the model of Dhomse et al. (dashed in mixing ratio vs. altitude), from the HALOE (solid) and the SAGE II v7 (dash-dot) ozone for 19922005. Horizontal bars are the RSS errors for the response profile from the SAGE II v7 ozone of 1992-2005.

crease for the SAGE II responses at 45 to $50 \mathrm{~km}$ compared with those of 1984-1998 and 1991-2005 indicates that the $11 \mathrm{yr}$ terms of 1992-2005 are influenced by the lack of the Northern Hemisphere's wintertime warming activity of the mid-1990s.

An analyzed EI-based ozone response profile for the 1979-2005 time period that is in terms of mixing ratio (MR) vs. altitude is adopted from Dhomse et al. (2011, their Figs. 5 and 6), and is included in Fig. 14. The EI-based response profile includes the effects of the observed changes in the atmospheric dynamics. Furthermore, the solar maximum, UVflux values are larger for 1980 and 1991 than for 2002. Thus, their modeled response profile from the EI-based time series ought to be larger than that from the HALOE time series of 1992-2005. Figure 14 has a modeled response near $35 \mathrm{~km}$ with a peak value of $2.8 \%$, while the analyzed response from HALOE is $2 \%$. Both response profiles decline to $1.5 \%$ at $30 \mathrm{~km}$ and to near zero at $45 \mathrm{~km}$, but then increase again from 45 to $55 \mathrm{~km}$. The shapes of the response profiles in Fig. 14 agree well from SAGE II v7 and HALOE. It is concluded that the SC-like response profiles from SAGE II and HALOE are mainly due to variations in the UV-flux forcing for the period 1992-2005.

\subsection{Effects of variations in temperature}

The SAGE II and HALOE responses in Fig. 14 differ in magnitude by $1-2 \%$, with the HALOE response being smaller. Vertical variations of atmospheric (and ozone) number density are smaller on a pressure surface than at the corresponding altitude level (Akmaev et al., 2006). It is tempting to try 
to relate the responses from SAGE II and HALOE by converting ozone number density vs. altitude (SAGE II units) to mixing ratio vs. pressure (HALOE units) or vice versa. However, the operational temperature data that accompany each of those satellite ozone data sets are uncertain (Randel et al., 2009). For instance, there is an apparent shift in the HALOE temperature time series in 2001 for altitudes below about $40 \mathrm{~km}$ (Remsberg and Deaver, 2005, their Fig. 4). This shift will lead to an incorrect trend of the pressure-altitudes that are used for the registration of the HALOE ozone profiles. The MERRA temperature time series that are archived along with the SAGE II v7 ozone appear reasonable below $40 \mathrm{~km}$, but they display a separate shift in 1999 at $50 \mathrm{~km}$ and above. Nevertheless, it is emphasized that the analyzed ozone responses from SAGE II v7 are based on number density vs. altitude. Its algorithms do not depend on temperature, except for the removal of Rayleigh scattering effects that are significant for the retrieved ozone in the middle mesosphere.

Ozone is negatively correlated with temperature in the upper stratosphere. Dhomse et al. (2011) report a positive solar response in upper stratospheric temperatures, and it reduces their modeled SC ozone response signal. Are there periods when the observed, decadal-scale responses in temperature are trustworthy for the upper stratosphere? The analyzed SClike temperature responses from two widely used reanalysis products, ERA-40 and ERA-Interim, were also provided by Dhomse et al. (2011); those max minus min responses varied from 1 to $2 \mathrm{~K}$ in the upper stratosphere. Remsberg (2009) also obtained an SC-like response for $T(z)$ of about $1 \mathrm{~K}$ at the low latitudes at $40-45 \mathrm{~km}$, which is an altitude region where temperature is a retrieved product from HALOE and where there are no apparent discontinuities in its time series.

Radiative temperature changes due to the observed trends in ozone and $\mathrm{CO}_{2}$ are largest at the low latitudes (Fleming et al., 2011). The rate of cooling in the upper stratosphere should have been greater in the 1980s, when ozone was being depleted significantly (Akmaev et al., 2006). Were the observed trends in upper stratospheric temperature greater in the 1980s? Temperature time series data from several ground-based lidar stations are considered as a benchmark for changes in $T(z)$, and they indicate that the cooling of the upper stratosphere was indeed larger for the period 19841998 than for 1992-2005 (Keckhut et al., 2011; Steinbrecht et al., 2009). Wang et al. (2012) and Thompson et al. (2012) also found global-mean, upper stratospheric temperature anomalies that are of the order of $-2 \mathrm{~K} \mathrm{decade}^{-1}$ from 1984 to 1995 , but nearly constant thereafter. The HALOE experiment provides the only other near-global, satellite temperature data set that extends for more than a decade during that latter period. Remsberg (2009) reported a trend in the uppermost stratosphere for HALOE $T(z)$ that is of the order of only $-0.5 \mathrm{~K} \mathrm{decade}^{-1}$ for $1991-2005$.

It is tentatively concluded that there is an SC-like response in $T(z)$ of $0-1.5 \mathrm{~K}$ from 35 to $45 \mathrm{~km}$, and that this response is very near to one from the EI data used by Dhomse et al. (2011, Fig. 5d) for simulations of their concurrent ozone response profile. It is also concluded that the trends in temperature, $T(z)$, were significant during the 1980s, but nearly constant from 1992 to 2005. These changes in $T(z)$ along with the negative correlation between ozone and temperature explain qualitatively why there is a smaller SC-like response from the SAGE II ozone number density time series of 19922005 (Fig. 14), as opposed to those of 1984-1998 (Fig. 13). It is also encouraging to see that the response profile in Fig. 13 from the simulations of Dhomse et al. (2011) for the longer period of 1979-2005 shows magnitudes that are midway between those from the SAGE II v7 ozone from its two separate, shorter time periods.

\subsection{Ozone trends}

Ozone number density at an altitude is affected in the upper stratosphere by changes of the reactive chlorine. Figure 15 shows the linear trends at $45 \mathrm{~km}$ from the analyses of the SAGE II v7 ozone for the two separate periods of 19841998 and 1992-2005. The vertical bars are the $1-\sigma$ uncertainties for the trend coefficients from the respective MLR analyses. The analyzed ozone trends for 1984-1998 for middle latitudes of the Northern Hemisphere agree closely with the ozone decreases from -6 to $-9 \%$ decade $^{-1}$ at $40 \mathrm{~km}$ reported by Steinbrecht et al. (2009) from ground-based lidar measurements from 1979 to the late 1990s. They also agree closely with trends from the v7 ozone obtained by Kyrölä et al. (2013). The trends from SAGE II are smaller for $1992-2005$ or -3 to $-5 \%$ decade $^{-1}$ at middle latitudes. At tropical latitudes the modeled ozone trends are from -3 to $-4 \%$ decade $^{-1}$ and related to the changing atmospheric chlorine (Fleming et al., 2011); the trends from SAGE II v7 support their model result. Tropical ozone trends from SAGE II v7 are less negative for 1992-2005 or about -0.5 to $-2.5 \%$ decade $^{-1}$ and with 1- $\sigma$ uncertainties of only $\pm 1 \%$ decade $^{-1}$. All other things being equal, this finding implies that reactive chlorine did not change by much between the two time periods. This finding agrees qualitatively with the average estimates of $2.8 \mathrm{ppbv}$ for total chlorine in the form of $\mathrm{HCl}$ during the period 1984-1998 and of $3.1 \mathrm{ppbv}$ for 1992-2005, or a difference of only $10 \%$ (WMO, 2003).

In general, the uncertainties for the trend terms are small and indicate that a linear term is a good fit to the data of the upper stratosphere for the relatively short, 13-14 yr time series shown in Fig. 15. Furthermore, even if the true trend for the time series is slightly nonlinear, that deficiency is effectively accounted for by the inclusion of the lag- 1 autocorrelation coefficient in the formulation of the terms of the final MLR models. Truncation of the ozone time series to minimize end-point anomalies following the Pinatubo event provides for significant trends from both the SAGE II and HALOE time series of 1992-2005. The small uncertainties for the results in Fig. 15 suggest that the analyzed trends are relatively unaffected by any bias in the associated $11 \mathrm{yr}$ 
SAGE II (45 km) and HALOE (1.7 hPa) Ozone

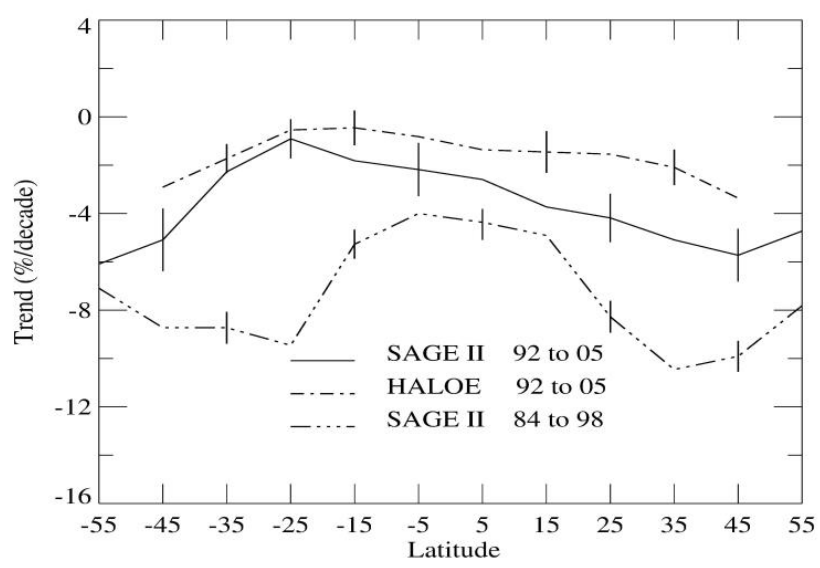

Fig. 15. Ozone trends ( $\%$ decade $^{-1}$ ) vs. latitude from SAGE II v7 at $45 \mathrm{~km}$ from both 1984 to 1998 and late 1992 to 2005 and from HALOE at $1.7 \mathrm{hPa}$ from 1992 to 2005 . Vertical bars are the $1-\sigma$ errors for the coefficients of the trend terms.

terms. Conversely though, a bias from the analyzed trend term can have a large effect on the diagnosed, SC-like ozone response profiles in Fig. 14. In fact, the amplitudes are small and sensitive to error for all the periodic terms of the MLR models in the upper stratosphere, as indicated for the SClike response profiles in Figs. 6, 13, and 14. It is concluded that this circumstance can easily lead to disparities between analyzed SC-like response profiles from observed data time series vs. those obtained from model studies.

The SAGE II results in Fig. 15 show negative ozone trends at $45 \mathrm{~km}$ that are larger in 1984-1998 than in 1992-2005. A part of that difference can be explained by cooling trends that are larger in the 1980s. In effect, ozone density should show a decrease with time due to a cooling or a contraction of its value at an altitude. Conversely, the HALOE trends in Fig. 15 are smaller than those from SAGE II for 1992-2005 because the effect of the cooling is already accounted for in the analyzed trends for HALOE in terms of ozone mixing ratio on a pressure surface. There is also a hemispheric asymmetry in the ozone trends in Fig. 15 from SAGE II of up to $4 \%$ decade $^{-1}$ for $1992-2005$, a result that is in accord with findings of Kyrölä et al. (2013). The ozone trends from HALOE at $1.7 \mathrm{hPa}$ are more nearly symmetric across the two hemispheres. The asymmetry in the SAGE II ozone is most likely a result of dynamical forcings. For instance, Fig. 16 shows the trend curves with latitude at the constant altitude of $45 \mathrm{~km}$ from SAGE II along with the concurrent SC-like response variations for the two time periods. There is hemispheric symmetry for both the SC-like response and the trend curves for 1984-1998, as expected from zonally averaged photochemical models. However, one can see that for 19922005 the SC-like responses increase positively with latitude in the Northern Hemisphere, while the trends increase neg-
SAGE II Ozone at $45 \mathrm{~km}$

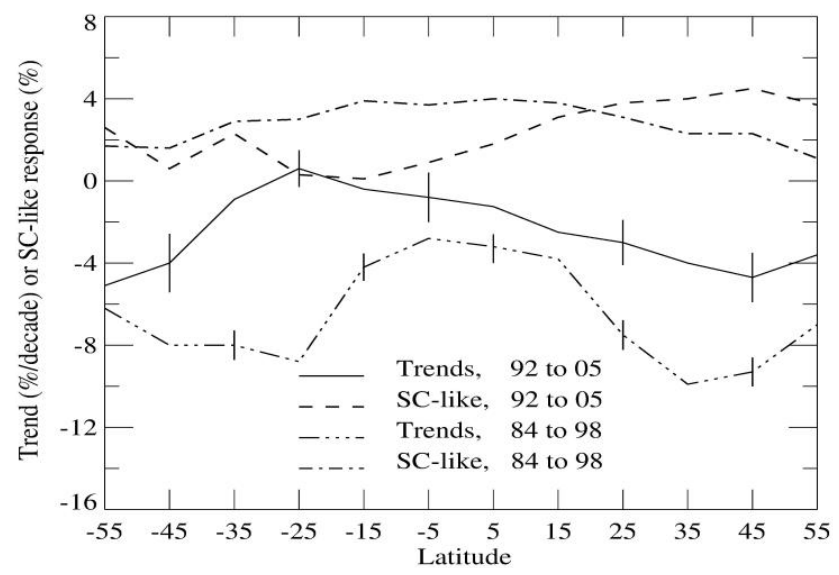

Fig. 16. Trends and SC-like responses vs. latitude for SAGE II ozone at $45 \mathrm{~km}$ for the periods of 1984-1998 and 1992-2005. Vertical bars on the trend curves are their $1-\sigma$ errors.

atively. A similar result is obtained from analyses of the HALOE ozone at the constant altitude of $45 \mathrm{~km}$ (not shown). Midwinter, wave-induced warmings were significant for the Northern Hemisphere for those years near solar maximum and lacking at solar minimum during the period 1992-2005, leading to a decadal-scale, vertical variation of the ozone surfaces near $45 \mathrm{~km}$ that was enhanced and in-phase with the solar forcing (e.g., Shu et al., 2013; Gerber, 2012; Solomon et al., 1986; Pawson and Naujokat, 1999). A further assessment of this likelihood is beyond the scope of the current study. Nevertheless, it is judged that the differences for the SAGE II and the HALOE ozone trends in Fig. 15 and for the analyzed SC-like responses for SAGE II in Fig. 16 are trustworthy for 1992-2005 because atmospheric perturbations that followed from the Pinatubo event have very little effect on the ozone time series of 1992-2005.

\section{Comparisons with other published SC-like ozone response profiles}

SC response profiles have been reported by RW (their Fig. 12a) based on their analyses of the SAGE I plus SAGE II v6.2 or the so-called SAGE-based ozone. They analyzed ozone time series at altitudes in terms of integrated ozone or DU km${ }^{-1}$, which is equivalent to ozone number density vs. altitude. Their response profiles for 1979-2005 have maximum values of about $4 \%$ at middle latitudes (after adjusting their results by the actual units of the F10.7 flux maximum), and the distributions herein (see Figs. 5 and 11) agree with them. However, their responses at the low latitudes are smaller, most likely because they are unable to fully resolve the response maxima from v6.2 and their relatively large interannual residuals compared with those from v7. Their inclusion of the SAGE I ozone may also be introducing biases 
for their analyzed ozone trend terms; the SAGE I ozone has yet to be reprocessed through the current $\mathrm{v} 7$ algorithm. RW considered monthly averages of SAGE profiles at every $5^{\circ}$ of latitude, or at much narrower bin widths than for the present study. Thus, it is expected that the random uncertainties for their analyzed SC-like terms ought to be larger by a factor of two. In other respects the component of the $\mathrm{v} 7$ ozone error in Figs. 6, 13, and 14 that increases with altitude is qualitatively similar to the levels of unexplained, interannual variance reported by RW (their Fig. 3).

Hassler et al. (2008) updated the ozone time series and climatology of RW, and merged them with ozone data from other, more recent satellite and ozonesonde measurements. McLinden et al. (2009) assembled a SAGE-corrected, time series of SBUV ozone for the purpose of providing better estimates of its long-term trends. Dhomse et al. (2011) analyzed those same SAGE-corrected, SBUV ozone data and compared those results with the findings from their simulation studies. Still, all of their studies used the SAGE v6.2 data, and the adjustments to the SBUV data of 1978-1981 were based on the SAGE I ozone that has yet to be reprocessed.

SH also analyzed SAGE II v6.2, HALOE v19, and SBUV v8 ozone for the time span of 1979-2003, but after deseasonalizing the data by removing their respective climatological mean values. For their analyses of the time series of the 3-monthly averages of the SAGE data, they did not include ozone from SAGE I nor from SAGE II past 2003; they also excluded just over two years of data following the eruption of Pinatubo. The present analyzed responses are similar to theirs for the middle latitudes. However, SH obtained max minus min responses for the low latitudes that are less than $2 \%$ between 28 and $36 \mathrm{~km}$. The present study finds responses from SAGE II that are also small at $30 \mathrm{~km}$, but which then increase to $3 \%$ at $35 \mathrm{~km}$ (see Figs. 13 and 14). It is judged that at least part of the difference with $\mathrm{SH}$ is a result of the improved accounting for the effects of the seasonal cycles in the SAGE II v7 data.

SH and Toupali et al. (2007) analyzed time series of monthly SBUV v8 ozone profiles from 1979 to 2003 for their solar cycle responses. Their analyses for the SC responses were performed on separate time series for each of the individual months or seasons. Both studies reported near zero $\mathrm{SC}$ responses from about 30 to $40 \mathrm{~km}$ at the low latitudes, contrary to the predictions of most photochemical models. Their response profiles from the SBUV ozone mimic those shown by Torres and Bhartia (1995, their Fig. 4) for the retrieval effects on ozone at higher altitudes, due to not accounting for multiply-scattered, UV channel radiances from a volcanic aerosol layer located at $26 \mathrm{~km}$. The effect of the aerosol scattering in the retrieval in that instance is a significant reduction in the ozone from 26 to $40 \mathrm{~km}$ and a small increase above $40 \mathrm{~km}$. Since the Pinatubo aerosol layer was present near solar-UV maximum, it is very likely that the effects of the scattering completely canceled the effects of the enhanced solar-UV flux. It is noted that SH did not exclude any SBUV data following the volcanic events of El Chichon and Pinatubo for their analyses, while Tourpali et al. (2007) deleted data for 1982 and 1991. RW were more conservative for their regression studies; they deleted two years of their merged SBUV v8 ozone following both volcanic events.

The SC-like responses of SH from the SBUV and SAGE II data are included in WMO (2007, Figs. 3-19) along with simulated responses from several models. One minor puzzle has been the increasing SC response values from the observations of SAGE II v7 and of HALOE at $50 \mathrm{~km}$ and above (e.g., Figs. 13 and 14), even though they are not very significant from the present analyses. Responses from the Brasseur model (and from many others) are near zero to negative at these altitudes. Yet, the response from the 3-D model study of Tourpali et al. (2003) is of the order of $2 \%$ at $50 \mathrm{~km}$, and that from the simulation study of Dhomse et al. (2011) increases from near zero at $45 \mathrm{~km}$ to $2 \%$ at about $55 \mathrm{~km}$. It may be that the increasing responses with altitude above the stratopause from the SAGE II and SBUV ozone analyses are largely real and a reflection of dynamical forcing mechanisms. As an example, Tourpali et al. (2003, Fig. 1) obtained SC-like ozone responses of $2 \%$ or more throughout the winter hemisphere at and above $55 \mathrm{~km}$, presumably due to dynamical rather than direct solar-UV forcings. A midto-late winter stratospheric warming and its associated lower mesospheric cooling activity can modify the annual ozone amplitude. Of course, such events tend to be more episodic, such that an MLR analysis would not fit the annual variations in the observed ozone variations well every winter. If mid-winter warming activity occurs more frequently near solar maximum than solar minimum (or vice versa), then it can represent an additional, decadal-scale forcing for the ozone in the upper stratosphere/lower mesosphere.

The role of changes in water vapor on ozone should not be ruled out either, especially for the mesosphere. Relatively low values of $\mathrm{H}_{2} \mathrm{O}$ will mean less ozone destruction via the $\mathrm{HO}_{\mathrm{x}}$ chemical cycle. Nedoluha et al. (2009) showed from the HALOE data that water vapor in the lower mesosphere was increasing at a rate of $1-2 \% \mathrm{yr}^{-1}$ from 1991 through 1996 and then remained fairly steady to 2005 . Such a trend will affect the analyzed solar response and trends in the ozone for 1992-2005. Less $\mathrm{H}_{2} \mathrm{O}$ (and $\mathrm{HO}_{\mathrm{x}}$ ) near solar max in 19911992 will mean that there is more ozone at chemical equilibrium with all other factors being constant. In situ observations in the lower stratosphere indicate that $\mathrm{H}_{2} \mathrm{O}$ was also increasing at a fairly steady rate of $1 \% \mathrm{yr}^{-1}$ through the $1980 \mathrm{~s}$ (Rosenlof et al., 2001). It is expected that those positive trends also extended to the mesosphere during that decade, but with a lag of several years. Thus, for the relatively short ozone time series of the present study the effects of such trends in $\mathrm{H}_{2} \mathrm{O}$ can confound an analysis of the concurrent SC-like term. More detailed studies of the decadal-scale effects of mid-winter warming events and/or trends in water vapor are beyond the scope of this report. 


\section{Conclusions}

This study is an extension of the analyses and findings in $\mathrm{RL}$, but it is based now on the newly processed SAGE II v7 ozone. MLR analyses for the period 1991-2005 were conducted, as before, and then additional analyses were made for the SAGE II v7 ozone of 1984-1998 and 1992-2005. The seasonal cycles fit the ozone time series of $\mathrm{v} 7$ much better than for the previous v6.2, and the MLR de-seasonalized residuals are smaller throughout much of the stratosphere for v7. As a result, the interannual and trend terms are resolved better and have greater significance than before, especially from 27.5 to $42.5 \mathrm{~km}$. It is judged that the SAGE II v7 ozone is of better quality.

The max minus min, $11 \mathrm{yr}$ ozone responses from SAGE II v7 for the period of 1984-1998 differ somewhat from those of 1991-2005 in the middle and upper stratosphere, but they are in-phase with the solar cycle UV flux at most altitudes and latitudes. The shapes of the SC-like response profiles from the SAGE II and HALOE ozone agree for the period of 1992-2005, or after deleting the first 14 months of data following the Pinatubo event and after taking into account the geophysical units of their respective data sets. At tropical latitudes and between 30 and $35 \mathrm{~km}$ the $11 \mathrm{yr}$ responses from SAGE II for 1984-1998 were lagging the UV-flux maximum by $1-2 \mathrm{yr}$ because of a separate perturbation that affected its ozone time series during the period 1989-1990.

Ozone trends in the upper stratosphere from SAGE II v7 extend to $-8 \%$ decade $^{-1}$ at the middle latitudes for 1984 1998. Model studies of the effects of atmospheric chlorine are generally consistent with that finding. The trends for 1992-2005 vary from about $-4 \%$ decade $^{-1}$ to near zero from the Northern to the Southern Hemisphere. Differences between the ozone trends from SAGE II at $45 \mathrm{~km}$ and from HALOE at $1.7 \mathrm{hPa}$ are also about $4 \%$ decade $^{-1}$ at northern middle latitudes but near zero at southern latitudes. Based on published diagnostic studies of others, it is inferred that the effects of wintertime wave forcings and their associated, induced net circulations are contributing to the difference in the Northern Hemisphere.

Acknowledgements. The author (EER) has benefited from the constructive comments of the two reviewers and from the recommendations of Editor, N. Harris. E. E. Remsberg also appreciates discussions with R. Damadeo, L. Thomason, and J. Zawodny of NASA Langley, regarding the quality of the SAGE II v7 ozone. Publication of the manuscript was supported with funds from the SAGE III Project. EER carried out this work while serving as a Distinguished Research Associate under the sponsorship of Malcolm Ko.

Edited by: N. Harris

\section{References}

Akmaev, R. A., Fomichev, V. I., and Zhu, X.: Impact of middleatmospheric composition changes on greenhouse cooling in the upper atmosphere, J. Atmos. Sol.-Terr. Phy., 68, 1879-1889, doi:10.1016/j.jastp.2006.03.008, 2006.

Baldwin, M. P. and Dunkerton, T. J.: Biennial, quasi-biennial, and decadal oscillations of potential vorticity in the northern stratosphere, J. Geophys. Res., 103, 3919-3928, 1998.

Brasseur, G.: The response of the middle atmosphere to longterm and short-term solar variability: a two-dimensional model, J. Geophys. Res., 98, 23079-23090, doi:10.1029/93JD02406, 1993.

Charlton, A. J. and Polvani, L. M.: A new look at stratospheric sudden warmings. Part I: climatology and modeling benchmarks, J. Climate, 20, 449-469, 2007.

Chipperfield, M. P., Gray, L. J., Kinnersley, J. S., and Zawodny, J.: A two-dimensional model study of the QBO signal in SAGE II $\mathrm{NO}_{2}$ and $\mathrm{O}_{3}$, Geophys. Res. Lett., 21, 589-592, 1994.

Chu, W. P., McCormick, M. P., Lenoble, J., Brogniez, C., and Pruvost, P.: SAGE II inversion algorithm, J. Geophys. Res., 94, 8339-8351, 1989.

Damadeo, R. P., Zawodny, J. M., Thomason, L. W., and Iyer, N.: SAGE version 7.0 algorithm: application to SAGE II, Atmos. Meas. Tech., 6, 3539-3561, doi:10.5194/amt-6-3539-2013, 2013.

Dhomse, S., Chipperfield, M. P., Feng, W., and Haigh, J. D.: Solar response in tropical stratospheric ozone: a 3-D chemical transport model study using ERA reanalyses, Atmos. Chem. Phys., 11, 12773-12786, doi:10.5194/acp-11-12773-2011, 2011.

Dunkerton, T. J.: Quasi-biennial and subbiennial variations of stratospheric trace constituents derived from HALOE observations, J. Atmos. Sci., 58, 7-25, 2001.

Fioletev, V. E.: Estimating the 27-day and 11-year solar cycle variations in tropical upper stratosphere ozone, J. Geophys. Res., 114, D02302, doi:10.1029/2008JD010499, 2009.

Fioletov, V. E., Tarasick, D. W., and Petropavlovskikh, I.: Estimating ozone variability and instrument uncertainties from SBUV(/2), ozonesonde, Umkehr, and SAGE II measurements: short-term variations, J. Geophys. Res., 111, D02305, doi:10.1029/2005JD006340, 2006.

Fleming, E. L., Jackman, C. H., Stolarski, R. S., and Douglass, A. R.: A model study of the impact of source gas changes on the stratosphere for 1850-2100, Atmos. Chem. Phys., 11, 85158541, doi:10.5194/acp-11-8515-2011, 2011.

Garcia, R. R., Solomon, S., Roble, R. G., and Rusch, D. W.: A numerical response of the middle atmosphere to the 11-year solar cycle, Planet. Space Sci., 32, 411-423, 1984.

Garcia, R. R., Marsh, D. R., Kinnison, D. E., Boville, B. A., and Sassi, F.: Simulation of secular trends in the middle atmosphere, 1950-2003, J. Geophys., Res., 112, D09301, doi:10.1029/2006JD007485, 2007.

Gerber, E. P.: Stratospheric versus tropospheric control of the strength and structure of the Brewer-Dobson circulation, J. Atmos. Sci., 69, 2857-2877, doi:10.1175/JAS-D-11-0341.1, 2012.

Hassler, B., Bodeker, G. E., and Dameris, M.: Technical Note: A new global database of trace gases and aerosols from multiple sources of high vertical resolution measurements, Atmos. Chem. Phys., 8, 5403-5421, doi:10.5194/acp-8-5403-2008, 2008. 
Hitchman, M. H. and Leovy, C. B.: Evolution of the zonal mean state in the equatorial middle atmosphere during October 1978May 1979, J. Atmos. Sci., 43, 3159-3176, 1986.

Hood, L. L., Soukharev, B. E., and McCormack, J. P.: Decadal variability of the tropical stratosphere: secondary influence of the El Nino-Southern Oscillation, J. Geophys. Res., 115, D11113, doi:10.1029/2009JD012291, 2010.

Keckhut, P., Randel, W. J., Claud, C., Leblanc, T., Steinbrecht, W., Funatsu, B. M., Bencherif, H., McDermid, I. S., Hauchecorne, A., Long, C., Lin, R., and Baumgarten, G.: An evaluation of uncertainties in monitoring middle atmosphere temperatures with the ground-based lidar network in support of space observations, J. Atmos. Sol.-Terr. Phy., 73, 627-642, doi:10.1016/j.jastp.2011.01.003, 2011.

Kyrölä, E., Laine, M., Sofieva, V., Tamminen, J., Päivärinta, S.-M., Tukiainen, S., Zawodny, J., and Thomason, L.: Combined SAGE II-GOMOS ozone profile data set for 1984-2011 and trend analysis of the vertical distribution of ozone, Atmos. Chem. Phys., 13, 10645-10658, doi:10.5194/acp-13-10645-2013, 2013.

Lee, H. and Smith, A. K.: Simulation of the combined effects of solar cycle, quasi-biennial oscillation, and volcanic forcing on stratospheric ozone changes in recent decades, J. Geophys. Res., 108, 4049, doi:10.1029/2001JD001503, 2003.

Manney, G. L., Krüger, K., Sabutis, J. L., Sena, S. A., and Pawson, S.: The remarkable 2003-2004 winter and other recent warm winters in the Arctic stratosphere since the late 1990s, J. Geophys. Res., 110, D04107, doi:10.1029/2004JD005367, 2005.

McCormack, J. P., Siskind, D. E., and Hood, L. E.: Solar-QBO interaction and its impact on stratospheric ozone in a zonally averaged photochemical transport model of the middle atmosphere, J. Geophys. Res., 112, D16109, doi:10.1029/2006JD008369, 2007.

McLinden, C. A. and Fioletov, V.: Quantifying stratospheric ozone trends: complications due to stratospheric cooling, Geophys. Res. Lett., 38, L03808, doi:10.1029/2010GL046012, 2011.

McLinden, C. A., Tegtmeier, S., and Fioletov, V.: Technical Note: A SAGE-corrected SBUV zonal-mean ozone data set, Atmos. Chem. Phys., 9, 7963-7972, doi:10.5194/acp-9-7963-2009, 2009.

Nedoluha, G. E., Gomez, R. M., Hicks, B. C., Wrotny, J. E., Boone, C., and Lambert, A.: Water vapor measurements in the mesosphere from Mauna Loa over solar cycle 23, J. Geophys. Res., 114, D23303, doi:10.1029/2009JD012504, 2009.

Pawson, S. and Naujokat, B.: The cold winters of the middle 1990s in the northern lower stratosphere, J. Geophys. Res., 104, 1420914222, 1999.

Randel, W. J. and Wu, F.: A stratospheric ozone profile data set for 1979-2005: Variability, trends, and comparisons with column ozone data, J. Geophys. Res., 112, D06313, doi:10.1029/2006JD007339, 2007.

Randel, W. J., Shine, K. P., Austin, J., Barnett, J., Claud, C., Gillett, N. P., Keckhut, P., Langmatz, U., Lin, R., Long, C., Mears, C., Miller, A., Nash, J., Seidel, D. J., Thompson, D. W. J., Wu, F., and Yoden, S.: An update of observed stratospheric temperature trends, J. Geophys. Res., 114, D02107, doi:10.1029/2008JD010421, 2009.

Remsberg, E. E.: On the response of Halogen Occultation Experiment (HALOE) stratospheric ozone and temperature to the 11-yr solar cycle forcing, J. Geophys. Res., 113, D22304, doi:10.1029/2008JD010189, 2008.
Remsberg, E. E.: Trends and solar cycle effects in temperature versus altitude from the Halogen Occultation Experiment for the mesosphere and upper stratosphere, J. Geophys. Res., 114, D12303, doi:10.1029/2009JD011897, 2009.

Remsberg, E. E. and Deaver, L. E.: Interannual, solar cycle, and trend terms in middle atmospheric temperature time series from HALOE, J. Geophys. Res., 110, D06106, doi:10.1029/2004JD004905, 2005.

Remsberg, E. and Lingenfelser, G.: Analysis of SAGE II ozone of the middle and upper stratosphere for its response to a decadal-scale forcing, Atmos. Chem. Phys., 10, 11779-11790, doi:10.5194/acp-10-11779-2010, 2010.

Remsberg, E. E., Bhatt, P. P., and Deaver, L. E.: Ozone changes in the lower stratosphere from the halogen occultation experiment for 1991 through 1999, J. Geophys. Res., 106, 1639-1653, 2001.

Rienecker, M. M., Suarez, M. J., Todling, R., Bacmeister, J., Takacs, L., Liu, H.-C., Gu, W., Sienkiewicz, M., Koster, R. D., Gelaro, R., Stajner, I., and Nielsen, J. E.: The GEOS-5 Data Assimilation System-documentation of versions 5.0.1, 5.1.0, and 5.2.0, NASA/TM-2008-104606, Technical Report Series on Global Modeling and Data Assimilation, edited by: Suarez, M. J., available at: http://ntrs.nasa.gov/archive/nasa/casi.ntrs.nasa.gov/ (28 January 2014), 2008.

Rosenlof, K. H., Oltmans, S. J., Kley, D., Russell III, J. M., Chiou, E.-W., Chu, W. P., Johnson, D. G., Kelly, K. K., Michelsen, H. A., Nedoluha, G. E., Remsberg, E. E., Toon, G. C., and McCormick, M. P., Stratospheric water vapor increases over the past half-century, Geophys. Res. Lett., 28, 1195-1198, doi:10.1029/2000GL012502, 2001.

Salby, M., Callaghan, P., and Shea, D.: Interdependence of the tropical and extratropical QBO: relationship to the solar cycle versus a biennial oscillation in the stratosphere, J. Geophys. Res., 102, 29789-29798, 1997.

Shu, J., Tian, W., Hu, D., Zhang, J., Shang, L., Tian, H., and Xie, F.: Effects of the quasi-biennial oscillation and stratospheric semiannual oscillation on tracer transport in the upper stratosphere, J. Atmos. Sci., 70, 1370-1389, doi:10.1175/JAS-D-12053.1, 2013.

Smith, A. K. and Matthes, K.: Decadal-scale periodicities in the stratosphere associated with the solar cycle and the QBO, J. Geophys. Res., 113, D05311, doi:10.1029/2007JD009051, 2008.

Solomon, S., Kiehl, J. T., Garcia, R. R., and Grose, W.: Tracer transport by the diabatic circulation deduced from satellite observations, J. Atmos. Sci., 43, 1603-1617, 1986.

Soukharev, B. E. and Hood, L. L.: Solar cycle variation of stratospheric ozone: Multiple regression analysis of long-term satellite data sets and comparisons with models, J. Geophys. Res., 111, D20314, doi:10.1029/2006JD007107, 2006.

Steinbrecht, W., Claude, H., Schoenenborn, F., McDermid, I. S., LeBlanc, T., Godin-Beekmann, S., Keckhut, P., Hauchecorne, A., Van Gijsel, J. A. E., Swart, D. P. J., Bodeker, G., Parrish, A., Boyd, I., Kämpfer, N., Hocke, K., Stolarski, R. S., Frith, S. M., Thomason, L. W., Remsberg, E. E., Von Savigny, C., Rozanov, A., and Burrows, J. B.: Ozone and temperature trends in the upper stratosphere at five stations of the Network for the Detection of Atmospheric Composition Change, Int. J. Remote Sens., 30, 3875-3886, doi:10.1080/01431160902821841, 2009.

Thompson, D. W. J., Seidel, D. J., Randel, W. J., Zou, C.-Z., Butler, A. H., Mears, C., Osso, A., Long, C., and Lin, R.: The mystery 
of recent stratospheric temperature trends, Nature, 491, 692-697, doi:10.1038/nature11579, 2012.

Tiao, G. C., Reinsel, G. C., Xu, D., Pedrick, J. H., Zhu, X., Miller, A. J., DeLuisi, J. J., Mateer, C. L., and Wuebbles, D. J.: Effects of autocorrelation and temporal sampling schemes on estimates of trend and spatial correlation, J. Geophys. Res., 95, 20507-20517, 1990.

Torres, O. and Bhartia, P. K.: Effect of stratospheric aerosol on ozone profile from BUV measurements, Geophys. Res. Lett., 22, 235-238, 1995.

Tourpali, K., Schuurmans, C. J. E., van Dorland, R., Steil, B., and Brühl, C.: Stratospheric and tropospheric response to enhanced solar uv radiation: a model study, Geophys. Res. Lett., 30, 1231, doi:10.1029/2002GL016650, 2003.

Tourpali, K., Zerefos, C. S., Balis, D. S., and Bais, A. F.: The 11-year solar cycle in stratospheric ozone: comparison between Umkehr and SBUVv8 and effects on surface erythemal irradiance, J. Geophys. Res., 112, D12306, doi:10.1029/2006JD007760, 2007.
Tung, K. K. and Yang, H.: Global QBO in circulation and ozone. Part I: reexamination of observation evidence, J. Atmos. Sci., 51, 2699-2707, 1994.

Wang, H. J., Cunnold, D. M., Thomason, L. W., Zawodny, J. M., and Bodeker, G. E.: Assessment of SAGE version 6.1 ozone data quality, J. Geophys. Res., 107, 4691, doi:10.1029/2002JD002418, 2002.

Wang, L., Zou, C.-Z., and Qian, H.: Construction of stratospheric temperature data records from stratospheric sounding units, J. Climate, 25, 2931-2946, 2012.

World Meteorological Organization: Scientific assessment of ozone depletion: 2002, Global Ozone Research and Monitoring Project, Report No. 47, Geneva, Switzerland, 2003.

World Meteorological Organization: Scientific assessment of ozone depletion: 2006, Global Ozone Research and Monitoring Project, Report No. 50, Geneva, Switzerland, 2007.

World Meteorological Organization: Scientific assessment of ozone depletion: 2010, Global Ozone Research and Monitoring Project, Report No. 52, Geneva, Switzerland, 2011. 